\section{EL FUTURO DE LA ARQUEOLOGÍA, ¿LA ARQUEOLOGÍA DEL FUTURO?}

\author{
THE FUTURE OF ARCHAEOLOGY: WHAT \\ IS THE ARCHAEOLOGY OF THE FUTURE?
}

\section{FELIPE CRIADO BOADO (*)}

\section{RESUMEN}

Este trabajo pretende revisar la situación actual de la Arqueología en nuestro país. De partida acepta que la atención al Patrimonio Arqueológico constituye el horizonte de aplicación y futuro de la Arqueología; ésta deberá integrarse en el ámbito de la gestión de los Recursos Culturales, adaptarse para representar un papel específico dentro de la creciente Industria Cultural, y reconvertirse como disciplina de gestión del registro arqueológico. Se argüirá que es necesario diseñar un modelo integral de gestión y estudio del Patrimonio, que posibilite unificar la práctica arqueológica y supere la equívoca dicotomía gestión-investigación. Ese modelo debe estar orientado a partir de programas de investigación bien definidos, que primen las urgencias generadas por las necesidades del Patrimonio, y garanticen la compatibilidad entre esas demandas y la producción de conocimiento nuevo. Para ello se propone reconvertir la Arqueología en una Tecnología y adoptar un modelo adecuado de registro arqueológico. Paralelamente, se examinan los problemas que hoy presenta la Arqueología con el fin de superar éstos de forma crítica. Se planteará el papel que la Universidad podría desempeñar en este contexto.

(*) Grupo de Investigación en Arqueología del Paisaje, Departamento de Historia 1, Universidade de Santiago de Compostela.

El artículo fue remitido en su versión final el 23-III-96.

\begin{abstract}
This paper deals with the present situation of Spanish Archaeology. It starts by accepting that attention to the Archaeological Heritage should be the applicable horizon for developing Archeology in the future: archaeological discipline should be understood as fully integrated in the management of cultural resources and adapted to play specific roles in Cultural Industries. For this, it is necessary to design an integral model of management and research of Archaeological Heritage, unifying archaeological practices and overcoming the confrontation between both activities. Such a model should be oriented from well-defined research programmes, giving priority to the actual demands of Archaeological Heritage and guaranting compatibility between such practical requirements and the production of ar-chaeological knowledge. It is proposed to shape Archaeology as a Technology and rethink the concept of archaeological record. The paper also examines some of the major problems which Archaeology faces at present and considers the role of the University in this situation.
\end{abstract}

Palabras clave: Patrimonio Arqueológico. Patrimonio Cultural. Arqueología Pública. Política arqueológica. Registro arqueológico.

Key words: Archaeological Heritage. Cultural Heritage. Public Archaeology. Archaeological politics. Re-search. Archaeological Record. 


\section{O. PATRIMONIO CULTURAL Y ARQUEOLOGíA}

En una situación caracterizada por el cambio de paradigma histórico, cuando las transformaciones en marcha en el empleo, la economía y la sociedad afectan por igual a todos los segmentos de lo social, derrumban los contornos familiares de un Régimen Moderno que ya parece Antiguo, y establecen nuevas reglas de juego de las que, si se dejan exclusivamente en manos de las fuerzas del mercado y son abandonadas por la crítica social, se puede suponer todo, menos que sean realmente justas, este trabajo intenta, modestamente, contribuir a un debate necesario sobre el papel de la Arqueología en ese contexto (1).

Para ello, se parte de la que parece ser la principal consecuencia en el ámbito de las Humanidades y la Cultura de ese proceso de cambio: la ampliación del concepto de Patrimonio Histórico, su transformación en Patrimonio Cultural (2), la emergencia de la necesidad de gestionar de forma ágil y rentable ese Patrimonio y, consiguientemente, la formación de una Industria Cultural en relación con esas actividades. La sociedad postindustrial, de la información y el ocio, genera una nueva actitud hacia el PH que no está determinada exclusivamente por los procesos y necesidades de constitución de la Identidad social.

A diferencia de la actitud moderna (constituida durante el siglo pasado y hegemónica en

(1) Este trabajo, como cualquier otro, tiene un contexto de génesis y significación. Por ello, debo reconocer la contribución de los compañeros con los que enfrento ese contexto (Fidel Méndez, Mariqui Martínez, Matilde González, Jesús Amado, Victoria Villoch, César Parcero, Lolo Santos, Pilar Prieto, Isabel Cobas y César González), así como el estímulo y aportación de aquellas personas que más me han ayudado para reorientar la práctica arqueológica dentro de esa situacion, entre ellas especialmente Rogelio Conde Pumpido y M. J. Tallón Nieto. Además, tengo que agradecer los comentarios de M. A. Querol, M. I. Martínez Navarrete, F. Infante y E. Rodríguez para precisar el texto.

(2) En este texto entendemos que el Patrimonio Histórico (PH en adelante) es una parte del Patrimonio Cultural (PC). Si mantenemos la primera denominación será bien porque ésta sigue siendo la más frecuente en la Arqueología, bien porque hagamos referencia exclusivamente a la parte histórica del PC. Igual sentido se otorga a la denominación Patrimonio Arqueológico (PA). Sobre la definición de ambos conceptos ver Querol (1995) éste), que encontraba en ese Patrimonio la fundamentación del Estado-nación y hacía de su estudio (la Historia) el discurso de legitimación fundamental, las nuevas estrategias de producción de la identidad (social y personal) en las sociedades finiseculares ya no necesitan apelar a la Historia y la Tradición. Una sociedad proteica, descentralizada, en la que se nos impone el mercado como árbitro de lo real y el individualismo como fuente esencial de legitimidad, produce un nuevo tipo de actitudes hacia el $\mathrm{PH}$, caracterizadas esencialmente porque éste deja de ser un valor absoluto y perenne y pasa a ser un bien estratégico y de uso. Este cambio se concreta en la transformación de un concepto de $\mathrm{PH}$ constituido por monumentos que deben ser conservados y restaurados con fidelidad al original, en un concepto constituido por mercancías que deben ser consolidadas y puestas en valor.

Independientemente de las opciones ideológicas y personales en relación con las transformaciones referidas, éstas están hoy entre nosotros y la definición y práctica de nuestra disciplina debe tomar posición en relación con ellas (3).

\section{LAS RESPONSABILIDADES DE LA ARQUEOLOGÍA}

\subsection{Ampliación y fragmentación de la Arqueología}

La Arqueología actual presenta, en nuestro país y en otros, un estado de buena salud. Aunque ello depende de la conjunción de una serie de factores compartidos por todas las naciones

(3) Este debate ya ha sido iniciado por otros trabajos y autores; nosotros nos centraremos en la discusión sobre los modelos de gestión del Patrimonio Arqueológico, concretamente en las relaciones entre investigación y administración de ese Patrimonio y entre los diferentes sectores implicados en todo ello; refiriéndose específicamente al caso andaluz, esta temática ha sido tratada desde posiciones semejantes a las que aquí mantendremos en Salvatierra (1994), así como en Ruiz (1989) y Ruiz et alii (1986); desde otros puntos de vista, se puede ver también Blasco y Valle (1992), Abad (1995), Domínguez et alii (1992) y Velasco et alii (1992). Recientemente, Benavides (1995) y Querol et alii (1995) recogen reflexiones importantes para contribuir a este debate y que, en cierta medida, están próximas a algunas de las propuestas que aquí se mantienen.

T. P., 53, n. ${ }^{\circ} 1,1996$ 
occidentales y relacionados en parte con las características de las sociedades post industriales emergentes (y a lo largo de este trabajo volveremos con cierto detalle sobre algunos de ellos), la principal causa material del desarrollo reciente de nuestra disciplina radica en el énfasis que han adquirido el Patrimonio Histórico y Arqueológico como Recursos Culturales.

Aunque los motivos y condiciones de este énfasis son bien conocidos, no está de más enunciar algunos de ellos en beneficio de la argumentación posterior:

- Tutela pública que el constitucionalismo reciente (Italia, Portugal y España) ha establecido sobre los bienes que integran ese Patrimonio por ser testigos del espesor histórico de nuestras sociedades.

- Necesidad de gestionar ese Patrimonio y solucionar los problemas que su presencia supone, conciliando ésta con la ordenación del territorio, con la política del suelo y con la planificación urbana.

- Valor social y económico que los bienes históricos adquieren dentro una creciente Industria Cultural.

- Necesidad de buscar fórmulas de desarrollo sostenible y de asegurar la conservación del medio.

- Tendencia a promocionar formas de turismo alternativo (ecoturismo, turismo cultural, etc.) basadas en la rentabilización socio-economo-cultural de los bienes históricos y arqueológicos.

- Finalmente, la utilidad de ese Patrimonio para fundar identidades específicas y legitimar procesos de emancipación y reivindicación por parte de diferentes colectivos sociales o étnicos.

Estos nuevos factores y necesidades han propiciado la constitución de un mercado que mueve alrededor de 6.000 millones de pesetas al año en toda España (4). La Arqueología es la disciplina humanística que mayor desarrollo ha experimentado durante la última década. De hecho, es la única entre las disciplinas históricas que ha sido capaz de configurar un sector profesional independiente de la docencia.

Pero estos desarrollos implican nuevos desafíos y problemas. Es necesario, como en cual-

(4) Esta cifra es el resultado de una estimación personal no contrastada y se basa en los presupuestos destinados a $\mathrm{Ar}$ queología por las diferentes CC.AA. quier otra ciencia, adaptar la Arqueología a las necesidades que han provocado el enriquecimiento actual de la Arqueología y, por ende, la pérdida del consenso tradicional en torno a su finalidad, orientación y métodos.

La historia de la Arqueología en los últimos veinte años es la crónica de su ampliación y, al tiempo, fragmentación continua. Cuando todavía no se ha cerrado el proceso que supuso la emergencia de la New Archaeology, la crítica del postprocesualismo y la explosión de las arqueologías alternativas, ni asimilado la variedad que todo ello generó, fisurando un campo que hasta ahora había dominado la Arqueología Académica y al que ésta confería una apariencia de unidad, surge un dominio nuevo de actividad vinculado al desarrollo y gestión del Patrimonio Arqueológico.

\subsection{Gestión e investigación, debates 0 dislates}

Así, en unos pocos años, la Arqueología, antaño disciplina exclusivamente académica y diletante, ha pasado a estar constituida por la coexistencia de cuatro sectores distintos: a los dos campos tradicionales representados por la $\mathrm{Ar}$ queología Académica o universitaria y la Arqueología Divulgativa o museográfica, se han unido con especial intensidad la Arqueología Pública y la Arqueología Comercial o Contractual. Aunque lo normal es que, para designar a estos dos sectores, se hable directamente de Arqueología de Gestión y se contraponga a la expresión Arqueología de Investigación, que representaría en cambio a los dos primeros, preferimos utilizar estos otros términos y clasificación porque nos parece más apropiado y honesto. A diferencia de la denominación habitual, esta otra no presupone, y menos prejuzga, el tipo de actividad arqueológica que el colectivo al que se refiere practica. Debemos intentar definir a los arqueólogos no por lo que son, sino por el contexto en el que actúan.

Con el término Arqueología Pública nos referiremos a la actividad arqueológica que se realiza desde instancias de las diferentes administraciones y que tiene como finalidad esencial administrar el PA y las competencias que sobre él mantiene el aparato del Estado en función de su interés social y utilidad pública. Y como 
Arqueología Comercial nos referiremos a la actividad que se genera en torno al PA cuando una gestión adecuada del mismo demanda la realización de actuaciones específicas que generalmente se desarrollan bajo contrato y, en todo caso, cumpliendo un determinado servicio y cobrando por él; como es bien sabido, este campo está ocupado fundamentalmente por pequeñas empresas y "consultings" de Arqueología que, sin embargo, las más de las veces no superan el umbral de una situación de precario auto empleo (5).

Se ha constituido así el campo cuatrifacetado, disperso y rico de la Arqueología actual. Pero han aparecido inevitables conflictos de interés, perspectivas y competencias entre los cuatro sectores (su estado actual de desarrollo fue descrito recientemente en Querol et alii, 1995). Se echa en falta un modelo de gestión de la Arqueología que permita armonizar las relaciones entre ellos e, incluso, unifique el trabajo de todos en un proyecto común. Si se sigue hablando de Arqueología es poco menos que en un registro retórico. Lo normal en cambio es que, con la boca pequeña, a veces atiborrada de palabras groseras, unos se nieguen a otros el estatuto de arqueólogos.

Es especialmente virulenta la confrontación en este sentido entre lo que algunos de los interesados en el conflicto denominan Arqueología de Investigación y Arqueología de Gestión. Desde ambientes académicos (6), sobre todo, es frecuente oír el reproche de que lo importante en la Arqueología es la investigación, aducido como crítica al hecho de que en la actualidad la mayor parte de los recursos económicos existentes se invierta en el campo de la

(5) Existe también dentro del campo de la Arqueología Comercial un área de actividad en la que convergen $\mathrm{y}$, por lo tanto, compiten arqueólogos y restauradores.

(6) No queremos ser injustos con muchos compañeros que se han esforzado y esfuerzan desde la Universidad por mantener la complementariedad entre ambas Arqueologías y adaptar el perfil de la investigación a las demandas de la gestión; su pensamiento y ejemplo es el que nos ha estimulado y servido de guía. Con todo, ese sector, aunque dinámico, es aún minoritario en el conjunto de la Arqueología Académica; se entenderá entonces que el carácter generalizador de las observaciones y críticas que se hacen a continuación no los comprende a ellos, sino que se deriva de la intención de referirse a todo lo que sigue constituyendo la normalidad académica. gestión del PA y por lo tanto reviertan fundamentalmente sobre las Arqueologías Pública y Comercial. En todas las Comunidades españolas, en muchos de sus cenáculos universitarios y en casi todas las capillas autonómicas, se está planteando este debate de forma cruda y el conflicto de forma violenta.

Este debate, sin embargo, ya se anunciaba en algunos trabajos (7) en los que se llamaba la atención sobre la necesidad de mantener la convergencia de la Arqueología en torno a su dimensión investigadora. El modelo andaluz, por ejemplo, se estableció sobre el principio básico de que "la investigación pura debía dirigir todo el proceso" (Salvatierra, 1994: 5). Sin embargo, pocos fueron los que se dieron por enterados y obraron en consecuencia. Además, incluso cuando se disponía de la mejor voluntad de convergencia entre ambas perspectivas, se generaba "un divorcio entre investigación y gestión" derivado de la carencia de "mecanismos reales de integración" entre ambas y de una auténtica "teoría de la gestión" (Salvatierra, 1995: 6) (8). Así y al cabo, ocho años después, este debate ha alcanzado su punto más ácido. La discusión de esta temática está centrada en varios temas importantes.

En primer lugar, procede aceptar que no se puede dar marcha atrás en el proceso de invertir en prioridades patrimoniales los escasos recursos de los que dispone la Administración pública. La invocación contraria por parte de los arqueólogos puede aportar elementos de

(7) Algunas de las voces más autorizadas (y tempranas), en este sentido, son Ruiz et alii (1986) y Ruiz (1989), donde se defienden el avance en la investigación y teoría arqueológicas como garantías de una auténtica protección y gestión del $\mathrm{Pa}$ trimonio Arqueológico. Ver Criado (1988); incluso en el artículo de réplica al anterior presentado por la APAE (Martínez Navarrete, 1988), aunque se criticaban algunas opiniones de nuestro trabajo, se mantenía la misma posición básica.

(8) Estas observaciones, aunque se refieren al "modelo andaluz", se podrían aplicar en general a todas las CC.AA. del Estado español. En general, al igual que ocurrió en Andalucía, el único mecanismo previsto a efectos de compaginar investigación y gestión fue y siendo "el tratar de integrar los registros de las urgencias en la investigación y consiste simplemente en asegurar la publicación de los informes" de esas intervenciones; pero esta reclamación, como dice el autor que seguimos, es en realidad un parche que no profundiza en la necesidad de desarrollar modelos integrales de gestión del Patrimonio, auténtica raíz del problema.

T. P., 53, n. ${ }^{\circ} 1,1996$ 
juicio que merezcan atención y consideración. Pero las prioridades de la conservación y acrecentamiento del PH son tales, que esta opción resulta bastante incuestionable. No se trata sólo de que haya que conservar, limpiar y proteger los bienes arqueológicos. Se trata sobre todo de que hay que inventariar, cautelar, ordenar, intervenir, documentar, consolidar, rentabilizar y divulgar esos bienes. Se trata de poner en marcha un programa global de actuación sobre el PA que, necesariamente, debe centralizar los recursos y el concurso de todos los sectores implicados. Ante ello, las prioridades, gustos e intenciones individuales, quedan arrinconados en un forzoso segundo plano. $\mathrm{La}$ excavación de un yacimiento singular para resolver un problema de investigación concreto, debe ser subsidiario en relación con el contexto general. Y ello no sólo por el imperativo legal que establece la cautela pública de los bienes de interés público, ni por el volumen de esfuerzo que éstos requieren, sino también porque la investigación se puede alimentar suficientemente, tanto en datos como en temáticas, a partir de la realización y resultados de esos programas globales.

Las reivindicaciones a favor de la investigación presentan, por demás, elementos muy paradójicos: sorprende por ejemplo que nadie exija la financiación del esfuerzo investigador en temas de Arqueología a las instancias rectoras de la política científica (CAICYT, Consejerías de Educación autonómicas...), y que en cambio se espere de las Direcciones de PH, como si los agrónomos o los ingenieros requiriesen a la Administración agrícola o de obras públicas para financiar sus investigaciones particulares, y criticasen la consolidación de una política agraria o de infraestructuras.

En segundo lugar, hay que reconocer que las demandas en beneficio de la investigación adolecen, en general, de una rigurosa conceptualización de lo que la investigación arqueológica deba ser y de su relación con la gestión del PA. Muchos arqueólogos académicos arguyen que resulta peligroso que todo gire alrededor de este, que es una dimensión de la Arqueología pero no su totalidad, y que la investigación se centre en lo que le interesa a la Administración, pues sus intereses, que priman la conser- vación, no son precisamente los que la comunidad científica y la Arqueología necesitan para avanzar como ciencia histórica.

Pero mientras tanto se manipula el lenguaje para hacer pasar por investigación la excavación de un yacimiento aislado, por ciencia la mera descripción de su registro, y por comunidad científica al colectivo de individualidades interesadas en mantener este status quo. Una manipulación, por demás, del mismo tipo que aquella que denomina "excavación sistemática" a la realizada por un profesor de Universidad durante veintiún días en verano, sin equipo, con alumnos a menudo de formación precaria y sin recursos técnicos suficientes; mientras el arqueólogo profesional que excava varios meses al año, interviene en un yacimiento de forma extensiva, trabaja con personal cualificado contratado y emplea instrumental y procedimientos de alta resolución, no sólo realiza "excavaciones de urgencia", sino que sigue cargando con el sanbenito de ser un arqueólogo sin formación suficiente. Éstos son, en parte, los problemas de haber pasado directamente del positivismo pre-científico al post-positivismo subjetivista. A este paso terminaremos deseando hacer la revolución burguesa (al menos en ciencia), en vez de apresurarnos a aprender de los límites de la modernidad para construir nuevos modelos de interpretación del mundo (también en Arqueología).

En tercer lugar, enmarcaremos las cosas en sus justos términos si aceptamos que lo que está aquí y ahora en juego es la configuración de un nuevo equilibrio de poderes dentro de la Arqueología y el Patrimonio Arqueológico. Las Universidades han sido tradicionalmente las depositarias del saber y las beneficiarias de su gestión. Esta situación, que fue hegemónica también en Arqueología hasta no hace mucho, se está quebrando precisamente ahora cuando, después de diez años de administraciones autonómicas, son éstas las que acaparan el arbitrio de la disciplina. Ellas tienen las competencias, los presupuestos, los programas de acción y prioridades, los recursos humanos y, en muchos casos, técnicos; son en definitiva las que poseen las intenciones y los medios para intervenir en Arqueología. Frente a su hegemonía, el anti- 
guo régimen representado por parte del profesorado de Universidad no puede hoy más que argüir el prestigio científico (9).

Entra dentro de la casuística de lo concreto que las Administraciones autonómicas muchas veces obren despóticamente, no cuenten con el asesoramiento de otros sectores o carezcan de una política arqueológica racional. Pero estos puntos sólo se pueden negociar e intentar cambiar si se acepta el principio esencial y previo, de que hoy la actividad arqueológica depende en su mayor medida de la Arqueología Pública. Aunque esto guste más o más bien menos. No se puede pretender deslegitimar la legalidad sólo porque a los individuos no les conviene. En cambio, lo que habría que exigir es que, quien acceda al poder, que lo ejerza, que lo ejerza bien y que se le pueda criticar por ello. Sin embargo, las Comunidades españolas no siempre cumplen estas condiciones y entre ellas hay, incluso, algunas en las que la Arqueología y la administración del Patrimonio Arqueológico poseen un estatuto de existencia que apenas alcanza una posición testimonial.

\subsection{La Arqueología como disciplina de gestión del Patrimonio Arqueológico}

Ante esta situación creemos que hay que restablecer la unidad de acción (o al menos de comunicación) en la Arqueología, recuperar las fórmulas de convivencia y cooperación entre los diferentes sectores que la constituyen y, sobre todo, establecer las bases de una adaptación de la Arqueología académica en concreto y de la Arqueología en general al nuevo contexto finisecular. Se trata con ello de responder a las demandas sociales que hoy nuestra disciplina está llamada a jugar.

Éstas y, sobre todo, las funciones relacionadas con la administración del PA, deben constituir el punto de referencia básico de la activi-

(9) En Querol et alii (1995: 244), al tiempo que se propugna la necesidad de que sea objetivo básico de toda intervención arqueológica la producción de conocimiento, y no sólo el "salvamento" de la documentación, se cuestiona la incapacidad del saber universitario para, a través de una adecuada estrategia divulgativa, crear una opinión pública sobre el Patrimonio e influir sobre su política. dad arqueológica y centralizar la mayor parte de la capacidad inversora. Pero al reconocer esto, se reconoce asimismo que la Arqueología sí tiene algo que vender pues, en contra de lo que aduce Abad (1995: 309), produce beneficios y puede ser rentable económicamente.

Esto no quiere decir que la Arqueología se deba limitar a ser un ejercicio meramente técnico e instrumental. Antes bien hay que readaptar nuestra disciplina para que sea capaz de subvenir a las demandas prácticas con una oferta de servicios cualificados y realistas (ap. 3.1). Esto supone, todavía, hacer mucha investigación, tanto de carácter aplicado como básico. Y no sólo porque haga falta desde un punto de vista utilitario, sino sobre todo porque los modelos de gestión del PA se deben basar en el doble postulado de que sólo se puede administrar lo que se conoce y de que esa administración es siempre una práctica interpretativa que manipula valores intelectuales.

Sobre esta base se podría empezar a reorientar la colaboración entre investigación y gestión del PA. Pero la convergencia de investigación y gestión demanda además restablecer las constantes de la Arqueología como práctica interpretativa y empresa de conocimiento; requiere definir un modelo teórico de la disciplina que permita unificar toda la variedad de actuaciones que dentro de ella se pueden hacer y que, necesariamente, se debe fundar en una conceptualización rigurosa del registro arqueológico (ap. 3.2). Esta readaptación de la Arqueología implicaría un determinado modelo de vertebración del mercado de trabajo y, dentro de él, del papel que compete a la Universidad (ap. 3.3). Este proceso de readaptación se enfrenta, sin embargo, a múltiples problemas.

\section{LOS PROBLEMAS DE LA ARQUEOLOGÍA}

La definición de Arqueología que seguimos en este trabajo es la que entiende a ésta como una estrategia de investigación que intenta describir e interpretar, a través del registro arqueológico, la integración de la Cultura Material en los procesos socio-culturales de construcción

T. P., 53, n. ${ }^{\circ} 1,1996$ 
social de la realidad. Desde esta posición intentaremos argumentar y entender las circunstancias a las que la Arqueología se debe adaptar en la actualidad y bajo qué condiciones debe hacerlo. Pretendemos, en beneficio de la discusión y el debate, proponer algunas posibles alternativas.

\subsection{Nuevas demandas, nuevos riesgos: mercantilización y cosificación en la Arqueología}

La necesaria reconversión de la Arqueología como disciplina de gestión de un determinado tipo de recursos culturales, que constituyen el PA, no se realiza sin riesgos. Todos los factores (enunciados más arriba) que influyen en el actual desarrollo de la Arqueología, implican el tratamiento puro y simple de los elementos arqueológicos como objetos, como cosas. Precisamente, por eso se pueden valorar y revalorizar, pues son objetos sancionados por un prestigio antiguo; comprar y vender, pues son objetos introducidos merced a la práctica arqueológica en el mercado; manipular y alterar, pues son objetos mudos.

La Arqueología encaja bien dentro del actual proceso de énfasis en los objetos, cosas y mercancías. Demuestra ser a la postre la ciencia social que mejor se aclimata a los tiempos que corren, de hegemonía de la imagen, la representación y el simulacro.

El registro arqueológico, al igual que cualquier registro histórico, está configurado por elementos (documentos) que vinculan su sentido original al sentido actual que la Historia construye en torno a ellos. Pero se diferencia de otros documentos históricos en que está conformado (fundamentalmente) por objetos que son testigos mudos de un pasado desvanecido, un complejo de productos sociales que han perdido su conciencia social. Esto implica ante todo que la reconstrucción de su sentido original no sólo presenta arduos problemas teóricos y metodológicos, sino que además constituye una hermenéutica en la que reaparece (como en cualquier operación de lectura o traducción) un plus de sentido actual y que puede ser fácilmente manipulada para transmi- tir y legitimar significados presentes (10). Este riesgo se ha exacerbado a través del postprocesualismo que, en vez de corregir ese problema limitando la interpretación y estableciendo sus límites teóricos, epistemológicos y éticos, ante la dificultad (cuando no imposibilidad) de esta tarea, ha claudicado proponiendo en cambio la libre aceptación de cualquier uso de la Arqueología (11). También aquí se ha convertido el mercado (es decir, el éxito de las propuestas arqueológicas) en el criterio de validación de las prácticas.

Pero además, como tales objetos, son forma y esto implica que pueden adquirir sentido por sí mismos, con total autonomía de su significación original o reconstruida. En una sociedad de mercado, que valora la pieza y la antigüedad, el valor del objeto arqueológico es independiente de su significación histórica (12).

(10) Esta característica de la interpretación ha sido resaltada por la filosofía hermenéutica (Giddens, 1982: 11; Gadamer, 1977: 332 y ss.). Su potencial manipulativo ha llevado a que en la actualidad se defienda la necesidad de limitar la interpretación; incluso los pensadores italianos que, desde el Eco de Obra Abierta, se habían destacado como los principales profetas de la hermenéutica libre, han reorientado sus posiciones en ese sentido (véase el propio Eco, 1991; Vattimo, 1995); asimismo, Fabbri (1995) establece que, incluso cuando se cree no decir nada, el discurso recrea un sentido que ya estaba dado en el horizonte de partida.

(11) En Shanks y Tilley (1987: 103 y ss.) ya se trataban las implicaciones para la interpretación arqueológica de la filosofía hermenéutica; sin embargo, en esa obra, siguiendo la tendencia dominante en la teoría postprocesualista de la pasada década, no se consideraban sus funciones o potencialidades manipulativas, sino que éstas eran valoradas como algo positivo y que permitía conciliar la Arqueología con las demandas del contexto social. Aunque el mismo Hodder (1991: 16) reconoció al término de la década "mágica" la necesidad de establecer un límite a la interpretación arqueológica, el postprocesualismo ha degenerado en muchos casos en una interpretación libre irremediablemente subjetiva (se puede ver como muestra de ello la obra individual de M. Shanks, por ejemplo, Shanks, 1992). Johnsen y Olsen (1992) han mostrado la pobreza filosófica de la Arqueología Contextual, especialmente de la obra de I. Hodder, y han atribuido esa degeneración subjetivista a una deficiente comprensión de la Hermenéutica. Esta problemática se traduce en las aportaciones del volumen editado por Hodder et alii (1995), algunas de las cuales muestran esa tendencia, mientras otras la critican o intentan superarla.

(12) Por significación histórica entendemos aquí el sentido original de un objeto o acontecimiento histórico; no equivale a su sentido reconstruido, que es el resultado de reinterpretar ese objeto en un contexto nuevo. Evidentemente, el valor de ese objeto depende en parte de su prestigio original, 
Obviamente, este rasgo es intrínseco al tráfico de antigüedades y, como tal, ha acompañado al origen y desarrollo de la Arqueología. Pero nunca fue tan hegemónico como ahora, pues ya no se trata de que esos objetos sean forma, sino de que como tales reportan una imagen y ésta, en la sociedad mediática, del espectáculo y el simulacro, se convierte en el soporte del auténtico valor económico del objeto, independientemente incluso de su valor como pieza preciosa o escasa.

En este contexto, la Arqueología enfrenta ahora la necesidad de entrar en el mercado y, paralelamente, el riesgo de mercantilizarse sin más. No es ajena a los procesos de cosificación que hoy dominan todas las escalas de lo social, que ponen al servicio de la ideología ultraliberal y técnica un mundo del que se hurta el sentido y en el que sólo permanecen los objetos y sus simulacros. La Arqueología, como disciplina que trabaja sobre objetos, se encuentra mejor posicionada que otros saberes para desempeñar una función "adecuada" dentro de ese sistema de poder. Son buen ejemplo de este riesgo tanto el éxito de la Arqueología entre el gran público, como su estado de buena salud que se contrapone a la actual crisis de la Historia [antaño saber legitimador por excelencia y que se correspondía a tiempos en los que la función legitimadora radicaba sobre todo en discursos textuales y literarios (13)] o, viniéndonos a cosas más concretas, ciertos montajes museográficos y políticas expositivas que se pueden observar hoy por doquier, caracterizadas por el privilegio de la forma pura reducida al estado de cosa y por la elisión simultánea de toda referencia al contexto, único umbral sobre el que se crea y se negocia el sentido.

antiguo, de los ecos que repite de un determinado contexto histórico, pero esa valoración le es otorgada de un modo que es relativamente autónomo en relación con ese contexto y que puede llegar, de hecho, a contradecirlo en beneficio del sentido nuevo.

(13) A estas alturas, dada la gran cantidad de autores y obras que, desde puntos de vista más o menos próximos, han tratado esta temática, no es realmente necesario detallar referencias; sin embargo, por tratarse de un autor español y procedente del campo de la Historia, hay que insistir siempre que Bermejo Barrera (por ejemplo, 1987 y 1994) ha profundizado con agudeza crítica en diferentes obras suyas en la crisis de la Historia.
Uno de los críticos más sagaces de la modernidad tardía, J. Baudrillard (1993), apunta notas sobre las que deberíamos reflexionar (Criado, 1988: 6 y 1989: 77). La Arqueología ha sido llamada a representar en la actualidad un papel importante: en una situación histórica que persevera en la ilusión de que nada es más importante que el instante presente, desnudo de pasado e incluso de futuro, la Arqueología, tomando el relevo de la Historia como instrumento de creación de identidad, ha adoptado la función práctica de compensar la pérdida del pasado, de la memoria cultural en el sentido de Nietzsche, creando un pasado artificial de fósiles, una quimera de pasado constituido por objetos mudos que, no pudiendo pronunciar su propio discurso, son convenientemente forzados a decir lo que convenga decir. No es casualidad que la Arqueología, disciplina de objetos, goce de especial buena salud en estos tiempos en los que las cosas han ocupado todo el espacio de las palabras. En este contexto, la Arqueología se beneficia de su buena disposición para convertir los objetos en signos vacíos o, en todo caso, en significados provisionales: una pieza puede significar algo y su contrario porque la pieza, muerto el sujeto que le confirió sentido, no tiene más sentido que el que le confiere el sujeto que la reencuentra una y otra vez.

Ante esta situación no es cierto que no exista alternativa. La hay. Pero seguirla es privilegio de cada cual. Modestamente, creemos que cinco son los hilos conductores de la alternativa.

En primer lugar, la Arqueología se debe resistir a entrar en los cauces actuales de la mera cosificación; debemos reinventar una Arqueología sin objetos, una Arqueología liberada de la atadura a las cosas-piezas, a los fósiles. En segundo lugar, debemos resistirnos ante la hipocresía arqueológica frente a la destrucción: el énfasis conservacionista en Arqueología, además de negar cínicamente la misma condición de existencia de la Arqueología (tanto de la profesional, como de la académica) que se construye sobre la destrucción del yacimiento arqueológico, tiene como racionalidad fundamental consolidar la sacralidad del objeto: detrás de la pulsión por conservarlo todo (las piezas, se

T. P., 53, n. ${ }^{\circ} 1,1996$ 
entiende), se esconde la intención de no conservar nada (la naturaleza, la memoria, los valores, las inmaterialidades inefectivas, se sobreentiende). En tercer lugar, en vez de conservar y enriquecer el Patrimonio mientras se destruye la vida social, se debe destruir un poco el Patrimonio para conservar la memoria, del mismo modo que, como ya Nietzsche aducía, se debe olvidar para poder recordar; se debe reivindicar la Arqueología como práctica constructora de conocimiento. Esto en Arqueología quiere decir que en vez de insistir en el dogmatismo de documentarlo todo, porque ese todo no existe, se deben forzar las palabras y el pensamiento para poder reinventar las cosas. En quinto lugar, y para todo ello, la Arqueología debe estar dentro de una Teoría de la Historia o, más en general, de una teoría que ofrezca modelos interpretativos coherentes de la realidad social.

Teniendo en cuenta estas observaciones, creemos que el principio que debe orientar la adaptación de la Arqueología y permitir superar muchos de los riesgos actuales, se debe basar en la asunción de que el PA no está integrado únicamente por bienes materiales, sino que éstos son además y ante todo valores intelectuales. En suma, que el PA no es algo que exista independientemente de la acción social, sino que es un conjunto de bienes producidos a través de la destrucción y gestión ordenada del registro arqueológico.

\subsection{Nuevos riesgos, nuevas necesidades: apuntes para una reconversión de la Arqueología}

Además del riesgo anterior, que a algunos podría parecer demasiado teórico, la Arqueología actual también presenta otros problemas concretos hacia los que nos debemos volver.

Formación. Así, empezando de hecho por el final, lo primero en lo que tenemos que insistir es en que la Arqueología necesita en nuestro país el amparo de una titulación universitaria específica y, a su vera, realizar una reforma en profundidad del plan de estudios. Mientras en otros países de nuestro entorno existe como título individual desde hace años, en España sigue siendo una mera línea de especialización curricular dentro de las carreras de Historia. De todos modos, antes de obsesionarse con la idea difícil de conseguir una Titulación de Arqueología, procede ensayar otras posibles soluciones de concreción práctica más sencilla. Nos referimos por ejemplo a la plasmación de Titulaciones en Gestión del PH o de Recursos Culturales dentro de los cuales tendría perfectamente cabida una línea de especialización curricular en PA (14). La potencialidad de esta solución se basa en apoyarse en otros dominios de desarrollo igualmente pujante que resultan compatibles con la Arqueología.

Financiación. Es necesario reclamar nuevos y decididos apoyos políticos, legales y administrativos para el ejercicio de la práctica arqueológica. En nuestro país la Arqueología se ha desarrollado hasta ahora gracias al amparo de la Administración que, al aplicar sus competencias de tutela y control del PA, ha demandado y fomentado las intervenciones sobre éste. Pero además, en un país como el nuestro en el que muchos segmentos del mercado dependen de la inversión y promoción pública, la Administración ha sido la mayor parte de las veces el promotor directo del trabajo arqueológico. Por lo tanto, en el actual contexto de recorte del déficit e inversión públicos, de predominio de las fuerzas puras del mercado y de supresión del Estado intervencionista, no está nada claro qué puede llegar a pasar con el incipiente mercado arqueológico aún no consolidado. En este dominio como en otros parece claro que, detrás de las demandas por cortar el desarrollo afuncional del sector público y fomentar en cambio la iniciativa privada, se esconde la intención de maximizar los beneficios del capital privado no poniendo coto alguno, en el caso que afecta al Patrimonio Arqueológico, a la especulación del suelo, a la privatización de los bienes realmente rentables y al desarrollo de acciones agresivas sobre el medio.

(14) Una solución de este tipo se ha apresurado, bajo la iniciativa de Arturo Ruiz, Vicente Salvatierra y Manuel Molinos, a poner en marcha la Facultad de Humanidades de la Universidad de Jaén, configurando así una experiencia pionera que muestra una alternativa posible para las restantes $\mathrm{Fa}$ cultades del Estado. Itinerarios semejantes tienen las Universidades de Santander y La Rioja, aunque no conocemos su organización (debo la información a M. ${ }^{\mathrm{a}}$ A. Querol). 
Cuando las recetas políticas y económicas de la Europa que viene, las demandas neoliberales para reducir el déficit e intervencionismo público $\mathrm{y}$, en definitiva, las transformaciones en marcha del Estado del Bienestar, no permiten estar seguros de cuál vaya a ser el papel de la Administración pública en la gestión del $\mathrm{PH}$, debemos demandar que se mantenga e incremente el amparo legal y político de éste por parte de aquélla. Debemos exigir que, al tiempo que aceptamos un recorte en los presupuestos públicos relacionados con el $\mathrm{PH}$, la Administración responsable de ese Patrimonio fuerce al sector privado a cumplir la legislación vigente y garantice así el mantenimiento de un mercado ágil en el que la iniciativa y financiación privada sustituyan cada vez más a la pública. En esto, como en otros sectores, se debe aplicar el principio de "quien deteriora, paga", en consonancia con la tendencia hacia una nueva fiscalidad que traslada el énfasis de la imposición sobre el trabajo hacia la utilización de recursos y la degradación de bienes escasos.

En este proceso se deben cumplir, en concreto, dos condiciones. La primera sería que la Administración sea cada vez más una Administración orientada hacia la gestión de servicios y el mantenimiento de las reglas generales de juego (cumplimiento de la normativa, conservación del Patrimonio y salvaguarda de los criterios de calidad) en vez de a la ejecución directa de esos servicios; de este modo se fomentaría la consolidación y desarrollo de un sector privado ágil. La segunda es que la Administración exija al que deteriora el bien no sólo la financiación de la intervención correctora, sino un programa de financiación que abarque desde la fase de proyecto hasta el trabajo de gabinete y elaboración de Memoria; sólo así se evitará el acopio de información descontextualizada y que se mantenga la ruptura entre intervención y conocimiento arqueológico que ya se había instaurado cuando no teníamos más que una Arqueología académica (15).

(15) Pues, a fin de cuentas, la improductividad o lentitud de los arqueólogos para publicar no empezó precisamente con la Arqueología de Rescate y, a pesar de que es frecuente criticar a ésta por no publicar los datos recuperados, se olvida que
Planificación (del suelo). No podemos estar seguros de que llegue a ser así. La política arqueológica depende, de un modo tan intangible como real, de la política del suelo. Es más, en el mismo sentido en que resulta, por desgracia, impensable que llegue a existir una política arqueológica sustantiva y propia, el desarrollo y configuración de ésta depende enteramente de la política del suelo. Pero en España sigue estando pendiente la transición arquitectónica, entendiendo por ello el desarrollo de una auténtica normativa de ordenación del suelo (rural y urbano) que compatibilice los diferentes intereses (públicos y privados, de respeto a la tradición y de modernización, de preservación del medio y dotación de servicios) que concurren en el uso del espacio social. La falta de esta normativa fue uno de los pilares de la política económica de la pasada década al haber fomentado el capitalismo inmobiliario y su posterior emigración al sector financiero y, después, una de las condiciones básicas del juego de intereses clientelistas y corrupciones en el que degeneró la política. Esa actitud no sólo se dio en el nivel de la alta política y el gran capital, sino que penetró capilarmente el conjunto del cuerpo social, hasta el extremo (notable en Galicia) de que los equilibrios políticos de cualquier ayuntamiento se dirimen principalmente en relación con el suelo y con los intereses de los propietarios.

La política del suelo constituye un ámbito de especial sensibilidad para todos los sectores sociales. Dada la relación entre ésta y el PH, tanto por ser sus bienes espacios concretos, como por las restricciones que éstos imponen al uso libre del espacio, no parece muy factible suponer que exista una auténtica política arqueológica mientras no se garantice la plena ordenación del medio.

Interpretación. Ahora bien, la formación, la profesión y la administración arqueológicas sólo serán de utilidad efectiva si se adapta la base metodológica y teórica de la Arqueología. En este sentido, ésta se encuentra impelida, y

este problema empezó antes de que se desarrollase aquélla; algún día habrá que evaluar comparativamente la relación inversión-publicación de las Aqueologías sistemática y “de urgencia”.

T. P., 53, n. ${ }^{\circ} 1,1996$ 
es sólo la resistencia de la disciplina tradicional la que frena la necesaria respuesta en este campo, a ofrecer nuevos esquemas interpretativos, algo que podríamos denominar nuevos patrones de (pre)historicidad, que permitan superar de una vez la obsoleta periodización tipológica heredada del siglo pasado que, en la misma medida en que reproduce la voluntad de saber tecnológica y productiva de la primera revolución industrial, ciñe nuestras mentes e inhibe la posibilidad de que una abultada nómina de especialistas dedicados a la investigación arqueológica seamos capaces de producir un mejor número de resultados. No se trata de hacer una Arqueología espectacular, sino de compaginar nuestra práctica con las corrientes de debate e investigación que ocupan actualmente el campo de las ciencias sociales, y cuya discusión resulta especialmente prioritaria en el contexto actual de cambio epistémico y social. Ya no llega ni tan siquiera con hacer Arqueología social o simbólica; tendríamos que desplazar de una vez por todas una terminología periódica que nos ata y encierra, que implica unos paradigmas interpretativos y una forma de proceder determinada. En este sentido, resulta especialmente perentorio desplazar la prioridad cronológica en la investigación arqueológica.

Temática. Necesita también la Arqueología explorar nuevas temáticas, ampliar su esfera de acción hacia dominios cronológicos y culturales habitualmente ajenos a su competencia. En esencia, la Arqueología es una disciplina que estudia la cultura material realizada por la humanidad observando como estos productos se vinculan a determinados contextos sociales. Aunque el ámbito específico de la Arqueología ha sido el pasado remoto, del que no quedan más huellas que sus materiales, la Arqueología podría también considerar la cultura material de otros momentos y situaciones históricos, incluyendo en ellos nuestro propio presente. Este trabajo debería ser tanto más urgente cuanto, si se considera con detenimiento, no existe ninguna disciplina que de una forma sistemática se dedique a estudiar la vida social de los objetos, pues la Historia del Arte, la Semiótica, la Sociología del Diseño o la misma Arqueología Industrial se centran en segmentos muy específicos de la Cultura Material.
Existe la posibilidad de desarrollar toda una Arqueología Histórica, tal y como propone S. Gutiérrez (1995a: 248; ver también Gutiérrez, 1995b) en un trabajo en el que decididamente apuesta por la "asunción del registro material moderno y contemporáneo como fuente histórica, tanto por los historiadores, como por los mismos arqueólogos". Esto ofrece la gran posibilidad de compaginar Historia y Arqueología, con lo que no sólo se podrán aproximar ambas disciplinas, sino que, al disponer de un registro escrito que refleja de forma más directa el patrón de racionalidad de la situación que se estudia, se podrían superar los problemas teóricos inherentes a la interpretación arqueológica y que, como vimos en el apartado anterior, conducen de un modo u otro al peligro de la manipulación del objeto histórico (primero) y a su cosificación (después). Y, a medio plazo, cuando se diluya la hegemonía de la actual prioridad en la gestión y rentabilización del $\mathrm{PH}$, será sin duda ese nuevo dominio el que permita todavía que los campos de estudio y aplicación de la Arqueología sigan creciendo.

\section{LAS POSIBILIDADES DE LA ARQUEOLOGÍA}

Si la Arqueología pretende generar una oferta que permita satisfacer el nuevo tipo de demandas prácticas que ahora, la mayor parte de ellas por primera vez, se le plantean, necesita reconvertirse y generar nuevos procedimientos de investigación e intervención sobre el PA. Para ello es necesario adaptar objetivos, metodologías y teorías.

\subsection{La Arqueología como tecnología}

A menudo se ha defendido la idea de que la Arqueología es en realidad una técnica, un procedimiento instrumental y auxiliar del saber histórico. Esta noción, que tuvo una cierta vigencia en nuestro país durante algún tiempo, recuperó nuevo vigor con el desarrollo de la Arqueología como actividad liberal. Parecería que el modelo de trabajo arqueológico que 
mejor se adapta a las necesidades de gestión del PA es el que se representase a aquél como una actividad aséptica y especializada.

Pero la Arqueología no es una técnica. Se pueden argüir varias razones para ello. En primer lugar, porque produce conocimiento, y no parece factible dejar en manos de una disciplina articulada como mera técnica la gestión y producción de conocimiento. Además, la Arqueología es una práctica que destruye los objetos con los que trabaja y, por lo tanto, la manipulación de los mismos no se puede dejar al técnico. Añádasele a ello que las condiciones de formación del registro arqueológico implican la operación de una instancia social que es previa al proceso de recuperación de ese registro. La imagen de la Arqueología como vulgar procedimiento es en realidad una quimera que alienta a los profesionales que, por las razones que sean, quieren servirse de ella de un modo utilitarista, y que apoya procesos manipulativos del tipo tratado en 2.1.

La Arqueología en cambio es un saber que permite hacer cosas. Estas cosas son cada vez más demandadas por una sociedad que tiene que utilizar el PA. Para hacer esas cosas no sólo se aplica un procedimiento instrumental, sino que su aplicación depende del conocimiento disponible sobre el contexto (arqueológico y social) considerado y, además, genera como valor añadido conocimiento nuevo.

En este sentido, la Arqueología es una tecnología. Vaya por delante que el concepto dominante hoy de tecnología es una caricatura de lo que el concepto significa. Por tecnología se entienden construcciones automáticas, fantasías maquinistas de funcionamiento ideal. En un cierto momento se ha confundido lo que la tecnología es como proceso con los resultados de ese proceso, y así se identifican como tecnología los productos, en vez de la producción. Porque tecnología es ante todo una forma de hacer cosas que implica a la vez un objetivo, un modo y un saber. Es, en su sentido más radical, una pro-ducción, un proceso que hace aparecer lo que no existía, que pone delante lo que falta. De este modo constituye la dimensión social de la técnica. Es técnica aplicada en un contexto, procedimiento basado en un conocimiento, efectividad derivada de una idealidad. De hecho, el sentido original de técnica en griego (técne) entronca con el verbo tícto, que significa precisamente pro-ducir (Heidegger, 1994).

En esta reorientación tecnológica las disciplinas históricas deberían remedar experiencias y transformaciones que, antes que ellas, sufrieron otras ciencias y disciplinas académicas. Es cierto que, tratándose de Humanidades, creerán muchos que esta reactualización de la Historia no sólo es improcedente sino imposible. Pero habría que recordar que lo que caracteriza a una tecnología no es ser de-ciencias o deletras, sino ser capaz de transformar un saber abstracto en un saber-hacer (Conde, 1994).

Por esta razón, la concepción de la Arqueología como tecnología no es opuesta, sino todo lo contrario, a su concepción como disciplina, metodología, teoría o saber. Si alguno recelase de que detrás de esta reconversión de la Arqueología se ocultan fantasías cientificistas, ideologías tecnocráticas y proclamas neoliberales, llegaría con argüir que la reducción de la tecnología a la técnica y la confusión de lo productivo con la productividad son los principales recursos de ese sistema de poder que, haciendo tabla rasa de las dimensiones sociales, simplifica el mundo para poder actuar de forma económica y automática sobre él. Como dice Lyotard (1984: 9 y 11), la modernidad la caracteriza la hegemonía de la ciencia como metarrelato y de la tecnología (su concreción) como fórmula de legitimación basada en el criterio de operatividad: "El criterio tecnológico permite definir qué funciona mejor o peor, no juzgar lo verdadero y lo justo." Pero la crítica de ese sistema de saber, la necesidad de subvertir la ideología del Hi-Tech, no proscribe de forma automática lo tecnológico, sino su uso sectario e instrumental.

En la actualidad, se está mudando de un conocimiento concebido como aprehensión de datos brutos, a uno que capacite al individuo para gestionar e interpretar los datos de su entorno, de un conocimiento presidido tiránicamente por la ciencia positiva, a uno que se comprende como práctica, experimento, "juego de lenguaje". Si se piensa bien, el saber ha sido siempre esto: una suma de tradición cultural, competencia, formación, conocimiento y ciencia que dotaban al individuo de todo lo necesa-

T. P., 53, n. ${ }^{\circ} 1,1996$ 
rio para desenvolverse de forma satisfactoria en su entorno (16). Por ello, la tecnología misma persiste como la capacidad para poner en práctica el saber. La Arqueología tecnológica no intenta hacer prevalecer la asepsia del procedimiento, otorgar más importancia a la técnica que a la teoría misma, sino mudar problemas en soluciones, reconvertir a la Arqueología en disciplina suministradora de servicios, orientada hacia objetivos efectivos, basada en programas eficaces, fundada sobre un conocimiento teórico y crítico. La Arqueología tecnológica deberá centrarse sobre todo en el diseño de nuevas metodologías y formas de ver el mundo.

Esta reconversión tecnológica implica, en la Arqueología al igual que en otras disciplinas, la necesidad de diferenciar entre una investigación básica y otra aplicada; mientras la primera perseguiría la ampliación del saber arqueológico en abstracto y la producción de innovaciones científicas y debería ser financiada fundamentalmente con cargo a los programas públicos de promoción del conocimiento, la segunda se debe orientar hacia el desarrollo de nuevas metodologías y procedimientos que permitan satisfacer demandas sociales en relación con la gestión de recursos culturales y, como tal, debe ser pagada por las Administraciones autonómicas o locales y por las empresas o instancias que actúan y degradan el PA. La información recuperada en las actuaciones de carácter prioritariamente patrimonial o de rescate, puede retroalimentar ambos tipos de investigación y contribuir al incremento del conocimiento arqueológico.

Sobre una base de este estilo se podrían articular programas coherentes e integrales de gestión del PA. Con ellos se garantizaría la satisfacción de las prioridades públicas, se maximizarían las inversiones, se unificarían los esfuerzos de los cuatro ámbitos implicados en la Arqueología (Administración, empresas, Universidad y museos), y se rentabilizarían todas las dimensiones de la actividad arqueológica.

(16) Definición que en este caso concreto tomamos de Lyotard (1984: 43) pero que es también la que constituye la noción foucaltiana de saber (Foucault, 1979).
Habría que demandar a las Administraciones competentes la articulación de unos planes racionales de gestión de ese Patrimonio que incluyan la necesaria atención a sus funciones metodológicas y cognitivas y que, sobre esas bases, funden su efectividad. Y habría que requerir a los investigadores para que respondan a estas demandas. Si, creyendo que el país no cuenta con alternativas en este sentido, hiciera falta buscar precedentes exteriores para ver qué hacer o cómo hacerlo, ejemplos como el Uplands Project en Gales o Inglaterra (Darvill, 1986), el Monuments Protection Programme en Inglaterra (Darvill, Gerrard et alii, 1993, Darvill, Saunders et alii, 1993) y su extensión en el proyecto MARS (Monuments At Risk Survey de la Universidad de Bournemouth y English Heritage), o la Megalithic Campaign en Dinamarca (Dehn, e.p.), podrían mostrar la senda a seguir.

\subsection{La gestión del Patrimonio Arqueológico como cadena interpretativa}

El desarrollo de la Arqueología como tecnología, como disciplina de gestión y manipulación del tipo especial de recursos culturales que constituyen el Patrimonio Arqueológico, se debe basar en la aceptación de ciertos postulados.

El registro arqueológico no preexiste a la observación actual que lo recupera; se construye a través de un proceso específico de formación en el que se conjugan múltiples instancias y circunstancias. Del mismo modo, el Patrimonio Arqueológico no es algo que nos venga dado; sino que depende de la consideración que sobre él vuelve un determinado contexto histórico, tal y como muestra el hecho de que hasta los albores de la modernidad no existiese algo así como el PA. Éste se genera a partir de valoraciones realizadas a través de prácticas sociales y, como tal, está constituido sobre todo por valores intelectuales adscritos convencionalmente a elementos físicos que existen fuera de la sociedad, pero que no-son nada sin ella, ya que fueron el producto de otra sociedad distinta que, una vez extinta, no puede dar cuenta de ellos. 


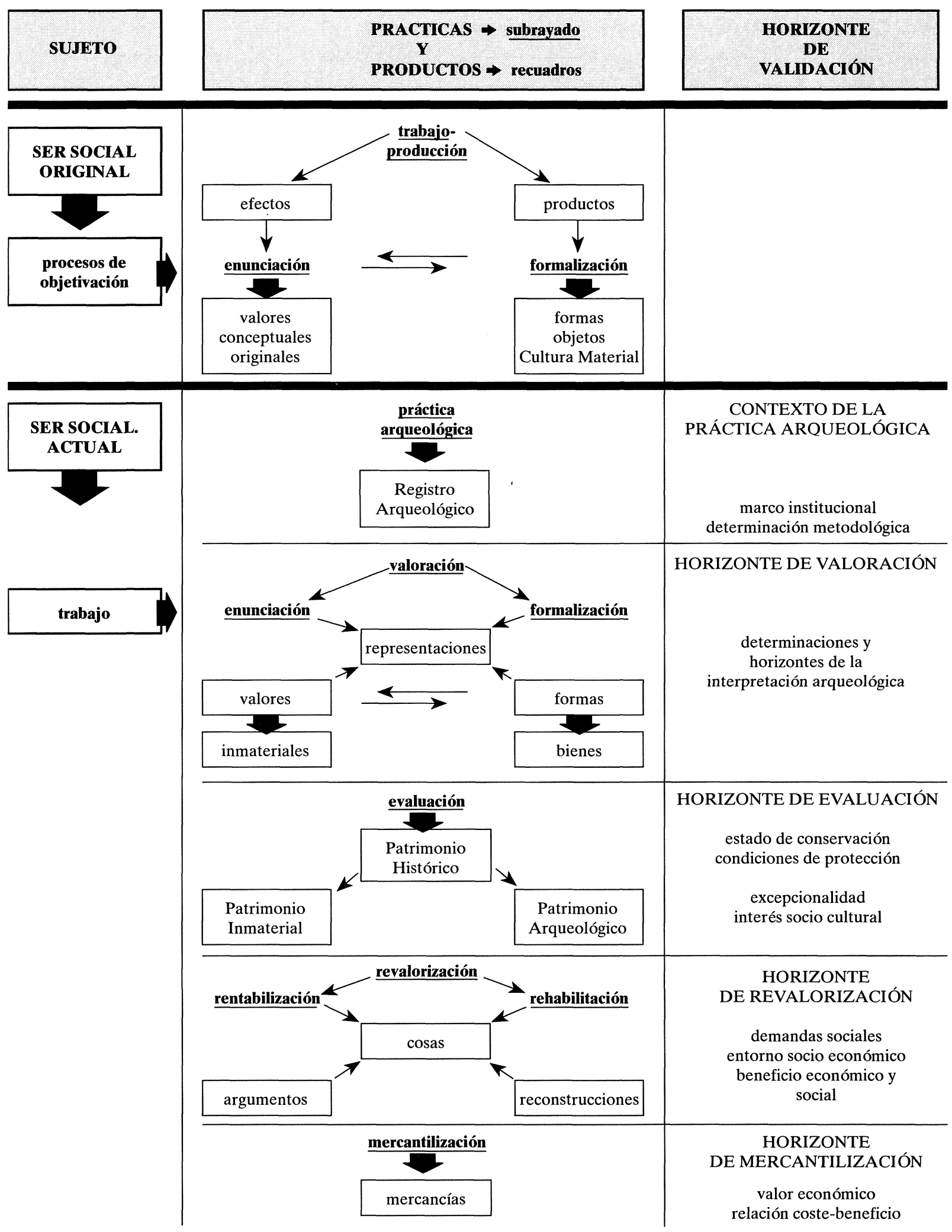

T. P., 53, n. ${ }^{\circ} 1,1996$ 
La Arqueología, como intervención que intenta restablecer el sentido original de esos objetos en un universo actual, tendrá que ser siempre una empresa intelectual, cognitiva, y la gestión de los recursos arqueológicos una práctica interpretativa realizada desde códigos concretos y en niveles diferentes. La Arqueología, sea Pública, Comercial, Académica o Divulgativa, se tiene que basar siempre en un modelo coherente de registro arqueológico. Su formación y, en concreto, la formación del PA (que es una parte privilegiada de aquél), depende de prácticas sociales actuales, determinadas por circunstancias contextuales concretas, y que constituyen un tipo de trabajo especial que, en realidad, adopta siempre el modo de una interpretación o valoración.

En un trabajo anterior (Criado, 1993) propusimos utilizar un modelo de registro arqueológico que entiende a éste como el registro de las formas producidas por la acción social pretérita y que muestran la orientación específica del contexto socio cultural (o pensamiento) hacia la realidad circundante (o mundo). Esto supone reconocer que en la formación de este registro intervienen tres tipos de instancias: una social y pretérita, que produce un conjunto específico de elementos formales originales; otra post-deposicional, que afecta a esos elementos a través de procesos físicos o ambientales; y otra social y actual, que los hace accesibles a través de un determinado contexto socio institucional en el que se realiza la práctica arqueológica. Este planteamiento posee implicaciones tanto para el conocimiento arqueológico, como para las restantes dimensiones o ámbitos de la práctica arqueológica.

En efecto, al plantear que el registro arqueológico posee una historia actual se acepta que aquél depende de un proceso valorativo que recoge los elementos arqueológicos como materia prima y los reintroduce en un contexto de uso actual dentro del cual adoptan valores nuevos (17). Ahora bien, la evaluación, que es un tipo especial de práctica teórica, no se

(17) Nuestra posición intenta seguir las propuestas de una epistemología realista (Gibbon, 1989; Lakoff, 1987) y de una teoría del significado que entiende que éste se crea lingüísticamente en el seno de "juegos de lenguaje" (véase Lyotard, 1984). puede confundir sin más con la mera opinión: se diferencia de ella en que es un estudio racional de supuestos alternativos basado en el diagnóstico de toda la información disponible (18).

La re-construcción arqueológica surge como el resultado de la aplicación y adición de prácticas valorativas sucesivas. Éstas constituyen una cadena interpretativa en la que unas valoraciones descansan sobre otras previas y en la que se pueden establecer diferentes niveles o tipos de valoración. Este proceso, aunque complejo, es factible de ser ordenado y regulado estableciendo niveles diferentes de prácticas arqueológicas en función de las características del proceso de valoración inmerso en cada una de ellas. Dado que en un trabajo reciente (Criado, e.p.) expusimos con detenimiento este modelo, simplificaremos la argumentación en beneficio de la brevedad (véase el resumen gráfico adjunto).

En primer lugar, se sitúa la valoración arqueológica estricto sensu (19) que se puede definir como la práctica interpretativa que intenta descubrir o estimar el valor original de un elemento del registro arqueológico. Esta práctica genera una representación o modelo descriptivo-interpretativo de las entidades arqueológicas que puede ser: material (es decir, bien o elemento arqueológico) o inmaterial (o sea, valor intelectual o conceptual). Es obvio que el primero implica siempre la existencia del segundo; pero la relación no es directa ya que un elemento puede connotar más de un valor intelectual.

(18) Definición tomada de Drucker (1988: 4). Es importante destacar esta diferencia porque, como conviene a veces recordar, la postmodernidad ha causado estragos: hemos llegado a una situación extrema en la que todo sujeto lingüístico expresa, por el mero hecho de hablar, opiniones, incluso cuando balbucea y éstas, además, son postuladas por unos y aceptadas por otros como verdades canónicas. Pero estos excesos derivan de haber olvidado las más elementales reglas a las que están sometidos las prácticas discursivas y los "juegos de lenguaje".

(19) En castellano "valorar" y "evaluar" son sinónimos; si utilizamos el término "valoración" en vez de "evaluación" para referirnos a esta fase es porque, dentro del lenguaje tecnocrático vigente en la gestión de recursos y del medio, el segundo ha pasado a denotar el acto de revisar problemas para hacer diagnósticos con finalidad práctica; éste es el uso dentro del cual aparece el término en la expresión evaluación de impacto ambiental (véase su definición en Gómez Orea, 1988). 
La validez de los modelos así producidos es siempre provisional y está en función de los ámbitos que, por así decirlo, constituyen de hecho el horizonte de validación de la valoración arqueológica en cuestión. Precisamente, por ello, ese modelo no tiene auténtica capacidad explicativa; pero tampoco puede depender exclusivamente de la subjetividad que lo enuncia), sino que debe poseer un nítido carácter inter-subjetivo.

En segundo lugar, se sitúa la valoración patrimonial y a la que llamaremos evaluación, entendiendo por ella la práctica interpretativa que intenta señalar o calcular el valor actual de un elemento del registro arqueológico desde el punto de vista Patrimonial. Esta práctica genera un modelo de gestión, protección y/o revalorización de esa entidad o grupo de entidades. Como tal, el principal resultado de la misma es la constitución del PA a partir del registro arqueológico.

La tercera fase de la valoración está constituida por la revalorización, que es una práctica interpretativa que convierte al PA en bienes (cosas, productos) factibles de entrar y funcionar dentro de los mecanismos del mercado, genera una alternativa que posibilita la rentabilización socio-cultural de ese conjunto, y supone por lo tanto una ampliación de su sentido y valor previo (20).

Se pueden diferenciar dos tipos diferentes de prácticas de revalorización: rentabilización sería la forma de revalorizar un elemento arqueológico a través de una acción intangible, dotando meramente a ese elemento de un argumento; rehabilitación en cambio sería la acción física sobre él. Mientras la primera puede funcionar de forma autónoma, debería ser regla básica en los procesos de revalorización aceptar que la segunda siempre debe acompañar a lo primero.

Existe todavía un nivel ulterior en los procesos de revalorización que nos conduce, de hecho, a otro tipo distinto de práctica: la mercantilización, o plena introducción de los bienes arqueológicos en el mercado. Para ello habría que añadir (otorgar o suponer) a las

(20) Esta última precisión se la debemos a nuestra compañera Matilde González Méndez. entidades arqueológicas un valor económico. Sería además la revalorización de un bien (un monumento) o valor (un catálogo) del PA contrastada ante el mercado.

Creemos que el conceptualizar la práctica arqueológica como un proceso de encadenamiento de valoraciones posee varias ventajas: 1) permite seleccionar los bienes que integran el PA y establecer niveles de gradación y prioridad entre ellos; 2) ofrece un modelo coherente e integral de gestión del PA, desde la fase de búsqueda y localización hasta, llegado el caso, su introducción en el mercado como bien económico; 3) ese modelo es lo suficientemente amplio y plural como para permitir que dentro de él quepan todos los dominios que hoy constituyen la Arqueología; y 4) posee una organización y equilibrio internos tal que permiten derivar de ellos un conjunto de normas que orientan como principios de acción práctica el ejercicio, coordinación e intercambio entre todos esos dominios.

Entre todas esas normas hay tres básicas. La primera es que la totalidad del trabajo arqueológico moviliza dimensiones interpretativas y cognitivas. La segunda es que cada nivel de valoración posee su propio horizonte de validación que justifica y fundamenta su aplicación. La tercera es que, si bien es legítimo un amplio elenco de intervenciones sobre el PA, su legitimidad procede, además del citado horizonte de validación, de su coherencia con las valoraciones previas.

\subsection{La función de las Universidades}

No queremos acabar estas notas sin apuntar la función que, desde nuestro punto de vista, debería competir a los Organismos Públicos de Investigación (OPIs), fundamentalmente las Universidades, en este contexto. Pues, aunque sean sobre todo los profesionales que trabajan en la Arqueología desde las Administraciones públicas o desde empresas privadas los que en mayor medida afrontan los retos de actualización urgente de nuestra disciplina, la superación de la mera proyección académica de la Arqueología, su adaptación como disciplina adecuada a la gestión del Patrimonio Histórico

T. P., 53, n. ${ }^{\circ} 1,1996$ 
y Arqueológico, y la misma vertebración del mercado de trabajo emergente, hacen necesario adoptar, también en la Arqueología, las aptitudes que, como arguye el Libro Blanco sobre el Empleo de la Unión Europea (21), requieren las transformaciones en marcha en el mercado de trabajo y en el conjunto social: "Aptitud para aprender, para comunicar, para trabajar en grupo, para evaluar la propia situación. ... Los oficios de mañana exigirán aptitud para formular diagnósticos y hacer propuestas de mejora en todos los niveles, exigirán autonomía, independencia de espíritu y capacidad de análisis basadas en el saber" (p. 35, Parte A). Capacidad, en definitiva, para gestionar información y conocimiento y aplicar éste a la resolución de problemas o situaciones concretas.

Los nuevos servicios relacionados con el $\mathrm{Pa}$ trimonio Arqueológico e Histórico, que pertenecen a ese grupo de oficios de mañana pero que ya están presentes, requieren formar un nuevo tipo de especialistas, abrir o consolidar nuevos mercados de trabajo y, simultáneamente, producir los instrumentos metodológicos y prácticos necesarios para operar en ellos.

En todo ello tiene una función que ejercer la Universidad. Evidentemente, no es necesario que esos desafíos se solucionen desde ella, y en realidad es muy posible que se solventen a expensas y sin contar con ella. Pocos indicios apuntan a que la Universidad española consiga recuperar algún día la conjunción con la sociedad y que se haga cierto el postulado del Libro Blanco según el cual "la cooperación entre las Universidades y el mundo económico constituye una vía fundamental de transmisión de los conocimientos, un vector de innovación y un factor de crecimiento de la productividad en los sectores en desarrollo, potenciales creadores de empleo" (pp. 207-8, Parte B, cap. 7.4).

(21) Nos referimos lógicamente al volumen Crecimiento, competitividad, empleo. Retos y pistas para entrar en el siglo XXI. Libro Blanco, preparado por la Comisión de las Comunidades Europeas y editado en Luxemburgo en 1993. La edición que utilizamos aquí es la reproducida y distribuida por la Fundacion Galicia-Europa (Santiago, 1994, 262 pp.). Para facilitar la identificación de las citas, se indicará, además del número de páginas, la referencia completa de la parte y capítulo a los que pertenece.
El cierre en falso de la reforma de los planes de estudio y la ausencia de una auténtica autonomía universitaria, que penetrase a ésta capilarmente y la dispusiera para poder competir y adaptarse con celeridad a las circunstancias cambiantes del entorno, en vez de limitarse a la falsa autonomía de administrar el presupuesto de personal y predeterminar los tribunales de plazas, no nos hacen suponer que en un futuro próximo se pueda concebir mayor optimismo en la capacidad de la Universidad para superarse a sí misma y, a continuación, superar los nuevos problemas emergentes en la sociedad.

Sin embargo, si los arqueólogos que trabajamos en la Universidad fuésemos capaces de responder a este contexto, ese esfuerzo se podría combinar con el ejercido por otras instancias para que todo redundase en beneficio de nuestra disciplina, en abstracto, y de los individuos que trabajan en ella, en concreto.

Lo primero que la Universidad puede y debe ofrecer en este contexto es una contribución decidida para mantener unida las prioridades de investigación con las de gestión del Patrimonio Arqueológico y superar así la nociva dicotomía que aquí hemos criticado. En ese sentido, puede formular programas de investigación que armonicen ambas prioridades y que equilibren las demandas de una investigación de carácter aplicado con el mantenimiento de una investigación básica en la que esa otra se pudiese fundar. En segundo lugar, puede actualizar los programas de estudio para formar a un nuevo tipo de especialistas, reorientando tanto la docencia de post-grado como la de grado y tendiendo a la institucionalización de estudios especializados, sino en Arqueología pura, al menos en Recursos Culturales y en los procedimientos de gestión de los mismos.

Estos objetivos, aun siendo positivos y complejos, son tópicos. Habitualmente, es lo que se espera de la Universidad. Pero ésta todavía puede ir más allá. A la Universidad debería competir liderar en parte la reorganización del propio mercado de trabajo. Desde las Universidades y organismos públicos de investigación se podría, utilizando sus recursos económicos, técnicos y humanos, cohesionar grupos de tra- 
bajo que pudiesen acometer los esfuerzos técnicos y de investigación que la galaxia atomizada de pequeñas empresas y arqueólogos autoempleados no puede asumir.

No se trata sólo de poner a punto procedimientos técnico-metodológicos que requieren cuantiosos esfuerzos. La Arqueología es, cada vez más, una actividad tecnificada, cara, y que requiere equipos costosos; es inviable suponer, por ejemplo, que la red de empresas de Arqueología actualmente existentes pueda dotarse de costosas infraestructuras de trabajo. Sobre todo, teniendo en cuenta la escasa cuantía de los presupuestos que se mueven en la actividad arqueológica y el hecho de que la mayor parte de éstos está comprometidos en personal.

En cambio, la Universidad puede poner a punto técnicas, equipos y laboratorios que, a precio económico, apenas cubriendo más que los gastos, se pueden ofertar a una red de pequeñas empresas que, de este modo, dispon-drían de mejores garantías de supervivencia al aliviar parte de los gastos de inversión y asegurarse, de todas formas, la posibilidad de acceder a procedimientos sofisticados. La Universidad podría así constituir unidades arqueológicas, que emanando de una entidad pública y con firme voluntad pública, funcionasen en cambio como grupos auto-financiados y pudieran jugar una función importante en un mercado dinámico.

Es cierto que esta función de las Universidades puede levantar muchos recelos, tanto dentro de los propios profesionales de la Universidad como entre los de fuera. Los de dentro alegarán sin duda que de este modo la Universidad se convierte en un consulting privado y pierde su propia y elevada naturaleza. Los de fuera argüirán que se pretende hacer competencia desleal al sector privado, cuya supervivencia ya atraviesa por ingentes peligros como para añadírsele un competidor más. Sin embargo, este tipo de funcionamiento, aunque inédito en la Arqueología, ya ha sido adoptado por la Universidad española en otros ámbitos del saber y por la extranjera dentro de la propia Arqueología (22). Sólo el tiempo y las prácticas

(22) En el Reino Unido, por ejemplo, son las llamadas Archaeological Units, que en unos casos son empresas priva- concretas podrán aliviar esas tensiones y mostrar que hay de cierto en una u otra opinión. Lo más probable es que, como en todo, algunas experiencias salgan bien y otras sean manifiestamente nocivas. Entre éstas, nosotros no dudaríamos en situar todas aquellas iniciativas que, prostituyendo el sentido último de la imbricación del saber universitario en este contexto, se planteen como meras empresas comerciales y operaciones privadas hechas desde el aparato público.

\section{PERSPECTIVAS}

De un modo que intenta ser coherente con una reorganización de las prácticas arqueológicas ajustada a la propuesta de cadena valorativa, así como con el proyecto enunciado de reconversión de la Arqueología en Tecnología, hemos planteado un programa de investigación que intenta ofrecer un marco posible para gestionar el registro y recursos arqueológicos. Este programa lo hemos basado en la Arqueología del Paisaje (23). Evidentemente, no es la única alternativa posible, ni pretende ser mejor que otras. Es sólo la que a nosotros se nos ocurre y que, desde nuestro punto de vista, presenta varias ventajas prácticas. En la actualidad, se tiende a ampliar el concepto de Patrimonio para comprender desde un elemento histórico concreto hasta el conjunto del paisaje como entorno construido y huella de la humanidad (24).

das, en otros servicios autofinanciados de instituciones públicas (Museos, Cámaras Municipales...), y en otros son una especie de unidad de intervención de los Departamentos universitarios de Arqueología (véase Lawson, 1994 o Jones, 1984: 26-30).

(23) Se pueden ver al respecto varias comunicaciones aparecidas en las Actas del Congreso Nacional de Arqueología celebrado en Vigo en 1993.

(24) Así se pronunció la convención Heritages for Europe convocada por el Consejo de Europa en septiembre de 1994. Ver también el volumen Macinnes y Wickham-Jones (1992), especialmente los artículos que consideran la interrelación entre $\mathrm{PH}$ y Patrimonio Natural desde el punto de vista de la administración común de ambos (por ejemplo, Kristiansen, 1992) y de las fórmulas de trabajo que posibilitan tratar el paisaje como una integridad que unifica PA, PH y PN (es interesante la propuesta de Lambrick, 1992). Posiciones semejantes son recogidas en Querol (1995) y Benavides (1995). 
Independientemente de este ejemplo, queremos creer que la definición y aplicación de programas integrales de éste u otro tipo debería ser el instrumento básico de gestión del PA. Resumiendo el análisis que hemos desarrollado en este trabajo, podemos apuntar varios principios orientadores para la puesta en práctica de estos programas.

Su diseño general debe partir de la necesidad de solventar el imperativo de orden patrimonial, atender después a la satisfacción de demandas sociales concretas, y unificar por último la perspectiva patrimonial y la de investigación conciliando posiciones que interesadamente tienden a plantearse como antagónicas.

Ahora bien, un programa no es una declaración de objetivos, ni la mera intención de hacer algo y ni tan siquiera una programación entendida como enumeración de trabajos a realizar. Esta acepción del término "programa" deriva del mal uso del mismo por parte de las instituciones de investigación o la Administración. En las primeras tiende a ser un disfraz para integrar aspiraciones individuales, a menudo contrapuestas entre sí, en un simulacro de plan unitario, y en las segundas una máscara para consolidar el vigor e inevitabilidad de una determinada línea de actuación. Dejando a un lado esta corrupción interesada del término, los programas de gestión que aquí se propugnan deben poseer las características y dimensiones necesarias para responder a las siguientes funciones:

1. Unos objetivos prácticos bien definidos y realistas.

2. Una definición de su alcance en términos de: rentabilización social, producción de conocimiento y satisfacción de demandas patrimoniales.

3. Una base teórico-metodológica explícita.

4. Un modelo de flujo y organización del trabajo, así como hipótesis orientadoras del mismo.

5. Una definición de los recursos humanos y técnicos disponibles y un plan de adaptación y formación de los mismos.

6. Un plan de intervención.

7. Un plan de integración de resultados y de formalización de éstos como productos factibles de ser rentabilizados de un modo u otro.

8. Un plan de diseminación de resultados, que integre pero vaya más allá de la publica- ción pues ésta es sólo una de las estrategias posibles de divulgación.

Dentro de estos programas correspondería a cada uno de los ámbitos de la práctica arqueológica una determinada función. La administración del Patrimonio debería adaptarse a las condiciones que establece la transición hacia la sociedad de la información y postindustrial:

1. Respondiendo ante todo a la demanda creciente de crear industrias culturales y del ocio.

2. Sustituyendo la burocracia moderna tradicional centrada en la administración de individuos y recursos, por una burocracia orientada hacia la gestión de servicios.

3. Basando la legitimidad de su acción en el diálogo y el consenso, como requiere una sociedad plural y descentrada en la que la realidad cotidiana la constituyen "juegos de lenguaje".

4. Enfocando ese consenso hacia funciones de coordinación y organización de programas de trabajo como los que aquí se proponen.

A las Universidades y OPIs les competería colaborar en las siguientes funciones:

1. Abrir campo de trabajo y experimentar nuevas líneas de acción.

2. Adaptar la Arqueología y desarrollar las metodologías necesarias para intervenir en esos campos (tarea de investigación aplicada).

3. Garantizar la compatibilidad entre gestión del PA y conocimiento (tarea propia de la investigación básica).

4. Ofrecer servicios especializados al sector público (Administración), al privado (compañías industriales y constructoras, fundamentalmente) y al profesional (empresas de Arqueología), apoyando así el desarrollo de la Arqueología en todos esos ámbitos.

El mercado de trabajo, por su parte, debería reorganizarse de modo que:

1. O bien se fomente la concentración de Empresas y la superación del excesivo desmigajamiento de la Arqueología Profesional centrada en trabajadores autónomos y autoempleados (25).

(25) Téngase en cuenta que, en Europa, la referencia de lo que es una Empresa de Arqueología lo aporta el MoLAS (servicio de Arqueología del Museo de Londres, institución pública autofinanciada, con una plantilla fija de 160 arqueólogos y hasta 250 incluyendo los temporales) o Arkeologikonsult (empresa privada sueca que cuenta también 200 con profesionales). 
2. O bien se fuerce la coordinación de todas esas instancias minúsculas en el seno de proyectos más amplios.

3. En todo caso, es preciso superar un modelo liberal de Arqueología Profesional que, intentando estimular la formación de Empresas, ha propiciado la fragmentación del mercado y de la fuerza de trabajo en grupos celulares que, a la postre, resultan más fáciles de controlar (26).

La divulgación debería ser concebida como la primera y principal forma de rentabilización; es necesario:

1. Garantizar la difusión de los resultados asumiendo no sólo que el trabajo arqueológico no publicado es patrimonio perdido (como avanzaba la Arqueología tradicional), sino que esos resultados (informes, memorias y sistemas de archivo) son en sí mismos registro arqueológico.

2. Aceptar que el incumplimiento de la obligación de escribir-publicar memorias es debido a la indefinición del carácter y alcance de la memoria, y a la falta de criterios estables de actuación profesional y de tratamiento de la información.

3. Que las estrategias de diseminación de resultados aprovechen las potencias de las nuevas tecnologías de la información y construyan

(26) Con todo nuestro respeto a lo que siempre son "iniciativas desde el filo", ejemplifica esta opción y sus problemas el llamado "modelo Madrid" (véase el dosier sobre Arqueología de Gestión publicado en el Boletín del CDL en Filosofía y Letras de Madrid, n. ${ }^{\circ} 55$, mayo de 1994). El efecto de este modelo se deja sentir en sus resultados: la Reunión de Arqueología Madrileña (celebrada en enero de 1996 y que fue prepublicada en un elaborado dossier gracias a la esforzada iniciativa del.Comité Organizador) muestra el despropósito que supone actuar en una misma ciudad a través de intervenciones puntuales y mediante instancias (empresas) autónomas: se pierde la posibilidad de recuperar la información en un proceso unitario de producción de conocimiento arqueológico que, al tiempo permitiría rentabilizar socialmente ese esfuerzo, retroalimentaría el propio trabajo de protección. Este es un problema común a la mayor parte de la Arqueología Urbana en nuestro país. Este modelo se puede comparar con el que representa el MoLAS, que además de garantizar la realización de un problema unitario de recuperación y estudio del Patrimonio Arqueológico de Londres, genera recursos económicos suficientes para mantener una gran empresa y produce valores intelectuales que, adecuadamente expuestos en el Museum of London, revierten en el público en forma de consumo cultural. formas de tratamiento y archivo de esta, que simplifiquen y abaraten el trabajo de elaboración.

Permanecen con nosotros varias dudas. Pero el peligro no debe cercenar la posibilidad, pues en Arqueología, como en otros campos, también se aplica el enunciado aquel que exige "reconciliar Cultura y Economía, obra y público, estructuras artesanales e imperativo industrial", que, aunque haya sido extraído del Libro Verde sobre el sector Audiovisual de la Unión Europea, marca muy claramente los desafíos a los que, como arqueólogos y ciudadanos, nos enfrentamos en este apurado final de milenio.

\section{BIBLIOGRAFÍA}

Abad Casal, L. (1995): "Arqueología, Universidad e Investigación". Actes de les Jornades d'Arqueologia (Alfàs del Pi, 1994): 303-12. Generalitat Valenciana. Valencia.

BAUDRILLARD BAUdRILlARD, J. (1993): La ilusión del fin. Anagrama. Barcelona.

Benavides Solís, J. (1995): "Siete enunciados sobre la teoría general del Patrimonio Cultural". Instituto Andaluz del Patrimonio Histórico, Boletín Informativo, III (12): 32-7.

Bermejo Barrera, J. C. (1987): El final de la Historia. Akal. Madrid

- (1994): Entre Historia y Filosofía. Akal. Madrid.

Blasco Aparicio, G. Y Valle Vega, J. M. (1992): “Arqueología de Gestión versus Arqueología de Investigación: el caso Madrid como paradigma". I Reunión de Arqueología Teórica, (Santiago, noviembre de 1992). Texto distribuido en el volumen precirculado de la reunión.

CONDE PUMPIDO, R. (1995): "Sobre as relaciós Universidade-Empresa e o V Centenario". El Correo Gallego, suplemento del V Centenario de la Universidade de Santiago de Compostela.

Criado BoAdo, F. (1988): “¿Qué es un arqueológo? ¿Qué es la Arqueología?" Revista de Arqueología, 82 (febrero): 5-7.

- (1989): "Megalitos, Espacio, Pensamiento". Trabajos de Prehistoria, 46: 75-98.

- (1993): "Visibilidad e interpretación del registro arqueológico". Trabajos de Prehistoria, 50: 39-56.

- (e.p.): "Hacia un modelo integrado de investigación y gestión del Patrimonio Histórico: la cadena interpretativa como propuesta". Instituto Andaluz del Patrimonio Histórico, Boletín Informativo, 1996.

DARVILL, T. (1986): Upland Archaeology: what future for the past?. Council for British Archaeology. London.

Darvill, T.; Gerrard, C. y STARTIN B. (1993): "Identifying and protecting historic landscapes". Antiquity, 67: 563-74.

T. P., 53, n. ${ }^{\circ} 1,1996$ 
Darvill, T.; SAunders, A. y Startin, B. (1993): “A question of national importance: approaches to the evaluation of ancient monuments for the Monuments Protection Programme in England". Antiquity, 61: 393-408.

Dehn, T. (e.p.): "The Megalithic Campaign. Principles and Methods in Restoration/Excavation of Danish preserved Passage Graves". En P.O. Nielsen y L. Heidemann (eds.): Megalithic Tombs: their Context and Construction. National Museum. Copenhagen, 1996.

Domínguez Alonso, R.M.; Fernández Ugalde, A.; Herce Yuste, J.L.; Menasanch de Tobaruela, M.; Moreno Lete, E.; Presas Vías, M. y Vigil-EscaleRA, A. (1992): "Arqueología Profesional e Intervención: reflexiones desde una experiencia cooperativa". I Reunión de Arqueología Teórica (Santiago, noviembre de 1992). Texto distribuido en el volumen precirculado de la reunión.

DRUCKER, P.F. (1988): "Llega una nueva organización a la empresa". Harvard-Deusto Business Review, 3 trimestre: $3-12$.

Eco, U. (1991): "Los límites de la interpretación". Revista de Occidente, 118: 5-24.

FABBRI, P. (1995): Táctica de los signos. Gedisa. Barcelona.

Foucault, M. (1979): La arqueología del saber. Siglo XXI. México.

GADAMER, H.G. (1977): Verdad y método. Fundamentos de una Hermenéutica Filosófica. Edic. Sígueme. Salamanca.

GibBon, G. (1989): Explanation in Archaeology. Basil Blackwell. Oxford.

GIDDENS, A. (1982): Profiles and critiques in social theory. MacMillan Press. Londres.

GÓmEz OREA, (1988): "Evaluación de Impacto Ambiental (EIA)". Ciudad y Territorio (revista del Centro de Estudios para la Administración Local), 75 (1): 5-32.

GutiéRrEZ Lloret, S. (1995)a: "La Arqueología después de la Edad Media: el registro arqueológico en la Historia Moderna y Contemporánea”. Actes de les Jornades $d^{\prime}$ Arqueologia (Alfàs del Pi, 1994): 237-53. Generalitat Valenciana. Valencia.

- (1995)b: "Fuentes materiales e historia contemporánea: unas reflexiones sobre la Arqueología Industrial desde la Arqueología". Actas de las I Jornadas Internacionales sobre Historia Contemporánea y Nuevas Fuentes (Alicante, 1995): sin pp. Universidad de Alicante. Alicante.

HeIDEGGER, M. (1994): "La pregunta por la técnica”. En M. Heidegger, Conferencias y escritos. Ediciones del Serbal. Barcelona: 9-37.

HodDer, I. (1991): "Interpretive Archaeology and its role". American Antiquity, 56(1): 7-18.

Hodder, I.; Shanks, M.; Alexandri, A.; Buchli, V.; CARMAN, J.; LAST, J. Y LUCAS, G. (1995): Interpreting Archaeology. Finding meaning in the Past. Routledge. London.

JoHnSEN, H. y Olsen, B. (1992): "Hermeneutics and Archaeology: on the philosophy of Contextual Archaeology". American Antiquity, 57(3): 419-36.

JONES, B. (1984): Past Imperfect. The story of Rescue Archaeology. Heinemann. London.
KRISTIANSEN, K. (1992): "From romanticism, throught antiquarism, to an historial view of nature: the case of Denmark". En L. Macinnes y C.R. Wickham-Jones (eds.): All Natural Things. Archaeology and the Green Debate. Owbow. Oxford: 52-64.

LAKOFF, G. (1987): Women, fire and dangerous things. What categories reveal about human mind. Chicago University Press. Chicago.

LAMBRICK, G. (1992): "The importance of the cultural heritage in a green world: towards the development of landscape integrity assessment". En L. Macinnes y C.R. Wickham-Jones (eds.): All Natural Things. Archaeology and the Green Debate. Owbow. Oxford: 105-26.

LAwson, A.J. (1994): "English archaeological units as contractors". En J. Hunter e I. Ralston (eds.): Archaeological Resource Management in the UK. An introduction. Alan Sutton/Institute of Field Archaeology. Bath.

LYOTARD, J.F. (1984): La condición postmoderna. Informe sobre el saber. Cátedra. Madrid.

MACINNES, L. Y WiCKHAM-JoNeS, C.R. (1992): All Natural Things. Archaeology and the Green Debate. Owbow. Oxford.

MARTínez NAVARRETE, M.I. (1988): “¿Qué es un arqueólogo? ¿Qué es la Arqueología? Algunas precisiones desde la APAE". Revista de Arqueología, 86 (junio): 5-6.

Querol, A. (1995). "Patrimonio Cultural y Patrimonio Natural: ¿una pareja imposible?". Homenaje a la Dra. D. ${ }^{a}$ Milagros Gil-Mascarell Boscà. Consejería de Cultura y Patrimonio, Junta de Extremadura. Cáceres: 301-6.

Querol, A.; Martínez-Navarrete, M.I.; Hernández, F.; CERdEÑO, L. y ANTONA, V. (1995). "The value of Archaeological Heritage: an analysis of the Professional Association of Spanish Archaeologists (APAE)". Journal of European Archaeology, 3 (1): 233-46.

RuIz RodríGueZ, A. (1989): "De las Arqueologías a la Arqueología". 1978-1988. Andalucía: diez años de Cultura: 9-17. Junta de Andalucía. Sevilla.

Ruiz Rodríguez, A.; Molinos Molinos, M. y Hornos MAtA, F. (1986): Arqueología en Jaén. (Reflexiones desde un proyecto arqueológico no inocente). Diputación Provincial de Jaén. Jaén.

Salvatierra Cuenca, V. (1995): "Historia y desarrollo del modelo andaluz de Arqueología". Trabajos de Prehistoria, 51 (1): 1-13.

SHANKS, M. (1992): Experiencing the Past: on the character of Archaeology. Routledge. Londres.

SHANKS, M. Y TiLley, C. (1987): Re-constructing archaeology. Cambridge University Press. Cambridge.

Vattimo, G. (1995): Más allá de la interpretación. Paidós. Barcelona.

Velasco Steigrad, F. y Comisión de Arqueólogos Del Colegio de Doctores y Licenciados de MADRID (1992): "Modelo de gestión y desarrollo profesional en la Comunidad de Madrid". I Reunión de Arqueología Teórica (Santiago, noviembre de 1992). Texto distribuido en el volumen precirculado de la reunión. 